ANUARIO DE Estudios MEDIEVALES

43/2, julio-diciembre de 2013, pp. 799-832

ISSN 0066-5061

doi:10.3989/aem.2013.43.2.11

\title{
DEVOCIONES REGIAS Y PROYECTOS POLÍTICOS: LOS COMIENZOS DEL MONASTERIO DE SAN BENITO EL REAL DE VALLADOLID (1390-1430) ${ }^{1}$
}

\author{
ROYAL DEVOTIONS AND POLITICAL PROJECTS: \\ THE BEGINNINGS OF THE MONASTERY OF SAN BENITO \\ EL REAL IN VALLADOLID (1390-1430)
}

CÉSAR Olivera SERRANO

Instituto de Historia (CSIC)

\begin{abstract}
Resumen: Este artículo estudia la primera época del monasterio de san Benito el Real de Valladolid desde su fundación en 1390 hasta la aparición de la congregación benedictina de Valladolid en 1431, sobre todo desde el punto de vista del apoyo regio. Se analizan las circunstancias que vivió Juan I de Castilla, destacando especialmente su proyecto de reforma monástica y su deseo de recuperar la corona de Portugal tras el desastre militar de Aljubarrota. Se estudian también las razones de la elección de la villa, las características del alcázar real y la instalación de exiliados de Portugal en el cercano barrio de Rehoyo. Juan I pretendía fundar una comunidad benedictina dentro de un espacio palaciego donde actuaban los miembros de la capilla real, aunque con el tiempo ganó terreno la comunidad benedictina y disminuyó el uso cortesano del monasterio.
\end{abstract}

Palabras clave: monasterios; palacios; Juan I de Castilla; orden benedictina; corte; capilla real; política regia; Portugal.

\begin{abstract}
This article studies the first period of the monastery of San Benito el Real in Valladolid from its foundation in 1390 to the appearance of the Benedictine Congregation of Valladolid in 1431, considering in particular the support from the king. It analyses the circumstances experienced by John I of Castile, emphasising his project of monastic reform and his wish to recover the Crown of Portugal after the military disaster at Aljubarrota. It also studies the reasons for the choice of the town, the characteristics of the royal 'alcázar' (castle) and the settlement of refugees from Portugal in the nearby district of 'Rehoyo'. John I intended to found a Benedictine community inside the palace complex where the members of the royal chapel worked, but over the course of time the Benedictine community increased while the court gradually stopped making use of the monastery.
\end{abstract}

Keywords: monastery; palaces; John I of Castile; Benedictine order; court; royal chapel; royal policy; Portugal.

1 Este artículo se inserta en el proyecto de investigación "Legitimación del poder, corrientes religiosas y prácticas de piedad en la corona de Castilla, siglos XII-XV”, HAR2008-04696/ HIST. Abreviaturas utilizadas: AHN = Archivo Histórico Nacional, Madrid; AGS = Archivo General de Simancas $($ EMR = Escribanía Mayor de Rentas); BSCV = Biblioteca de santa Cruz, Valladolid. 


\section{SUMARIO}

1. Introducción.- 2. Los antecedentes de la fundación.- 3. La cuestión de las fechas fundacionales.- 4. Los textos fundacionales de san Benito el Real de Valladolid.5. Un enclave atípico.- 6. La primitiva dotación económica.- 7. Exiliados de Portugal en el entorno de san Benito el Real.- 8. Conclusión.-9. Bibliografía citada.

\section{INTRODUCCIÓN}

La historia del monasterio de san Benito el Real de Valladolid cuenta en su haber con una dilatada producción bibliográfica ${ }^{2}$ que se explica principalmente por dos razones. Primero por su importancia como centro renovador de la observancia benedictina castellana de los siglos XV y XVI, y en segundo lugar por la difusión de esa observancia a través de la congregación de monasterios que formó a partir de $1431^{3}$. Muchos de los títulos publicados se refieren, como es lógico, a la faceta estrictamente monástica, incluyendo las formas de espiritualidad que se impulsaron desde el interior de su clausura ${ }^{4}$. Estas cuestiones están estrechamente unidas a la historia de la propia congregación de modo que no es fácil deslindar campos entre ambas realidades.

Junto a la trayectoria estrictamente monástica o religiosa se han estudiado otras cuestiones complementarias como su patrimonio económico y sostenimiento material, los vínculos con el entorno social de la villa o los contactos con el mundo cortesano ${ }^{5}$, sin olvidar su importante patrimonio artístico y cultural $^{6}$. Muchas de estas facetas se han podido investigar a partir de la rica colección de textos que se acumularon en los anaqueles de su biblioteca y archivo, aunque en el siglo XVIII se desgajaron los fondos referidos a la congregación (custodiados en su mayor parte en la biblioteca de santo Domingo de Silos) de los del propio monasterio; estos últimos se conservan principalmente en la sección de Clero del Archivo Histórico Nacional.

2 Destacan los estudios de E. Zaragoza, Los generales; idem, Abadologio del monasterio, pp. 203-260.

3 G.M. Colombás, M.M. Gost, Estudios sobre el primer siglo de San Benito; G.M. Colombás, El Libro de los bienhechores.

4 Destacan los estudios de E. Zaragoza; La práctica de la contemplación; idem, Libros que alimentaban la vida; idem, La práctica de la oración metódica; idem, Reglas y avisos.

5 El estudio fundamental sigue siendo el de A. Rucquoi, Valladolid en la Edad Media, vol. II.

6 Para los aspectos históricos generales y artísticos véase J. Rivera (ed), VI Centenario: Monasterio de san Benito; L. Rodríguez Martínez, Historia del monasterio de san Benito; J. Moreda Blanco et al., El Monasterio de San Benito. 
San Benito el Real contó con una historiografía propia dentro de la orden benedictina, lo cual da idea de su inmenso prestigio durante la Edad Moderna. Los historiadores del monasterio y de la congregación ${ }^{7}$ emplearon todos los fondos disponibles hasta el momento en que se dividió el conjunto documental, pero sobre todo siguieron las pautas marcadas por el principal historiador del monasterio, fray Mancio de Torres, que elaboró su obra en 1622. Gracias a su condición de archivero fray Mancio compuso una historia detallada y completa desde los orígenes hasta el siglo XVII, preservando del olvido algunos documentos importantes que hoy ya no se conservan ${ }^{8}$. Es un texto que merecería una edición crítica porque sigue siendo útil. Ahora bien, algunas de sus explicaciones sobre los primeros tiempos dan por descontado que ya estaba presente la semilla de la expansión, como si la congregación estuviese prevista en los comienzos. Esta interpretación, elaborada muy a posteriori, distorsiona una parte de la realidad. En efecto, los "monjes prietos" que se afincaron dentro del recinto del antiguo alcázar acabarían siendo el germen de una renovación profunda del monacato benedictino, pero es importante destacar que la expansión no fue un hecho coetáneo a la fundación, sino bastante más tardío, ya que se desplegó a partir de 1431. Por tanto, durante los primeros cuarenta años de vida no hubo congregación ni tampoco era posible predecirla.

Este aspecto es importante para entender el verdadero sentido que tuvo la decisión del rey fundador. San Benito el Real no partió de una realidad monástica anterior más o menos decaída o reformada, tal y como sucederá después con muchos centros benedictinos sometidos a su autoridad, sino que nació gracias a un empeño personal de Juan I. El monarca quería un monasterio modélico en la práctica de la observancia benedictina en una época especialmente dura para él, sobre todo después de sufrir un tremendo correctivo en la guerra de Portugal. Buscaba la cercanía de unos monjes dedicados a la oración para obtener la protección divina ante los retos que tenía en el horizonte inmediato.

Cuando se trata de entender la trayectoria de una institución eclesiástica, sobre todo si es monástica, hay que prestar una especial atención al sentido que tienen los documentos fundacionales, ya que el desarrollo de la institución se explica -al menos en parte- a partir de los fines que se proclaman en esos textos. Los de san Benito el Real ya han sido glosados con de-

7 E. Zaragoza, Cronistas generales.

8 Mancio de Torres, Libro primero de la Historia de san Benito el Real de Valladolid, copia manuscrita del siglo XVIII, BSCV, Ms. 195. Versión digital en http://uvadoc.uva.es/handle/10324/353 [consulta: 18/01/2012]. 
talle $^{9}$ desde el punto de vista de la espiritualidad benedictina, pero es preciso completar esa visión con el contexto histórico que se vivió en la etapa inicial.

\section{LOS ANTECEDENTES DE LA FUNDACIÓN}

Se admite de manera general que la iniciativa de Juan I responde a un deseo de renovación de la vida monástica que ya se percibe en los comienzos del reinado ${ }^{10}$. También se acepta que esa preocupación responde a una característica bastante acusada de su personalidad, el sentido religioso del oficio regio, manifestado a través de los documentos de la cancillería, de los textos legislativos y de la crónica del reinado que elaboró el canciller Pedro López de Ayala. El rey se rodeó de un selecto grupo de eclesiásticos igualmente preocupados como él en promover la reforma del clero castellano, tanto secular como regular. Entre los más influyentes destaca su confesor, el franciscano fray Fernando de Illescas, que inició en 1380 una labor renovadora en el ámbito de las clarisas con la reforma observante del convento de Tordesillas, germen de una conocida familia monástica que se expandirá desde muy pronto por la corona de Castilla ${ }^{11}$, o el arzobispo de Toledo, Pedro Tenorio ${ }^{12}$, entre otros más que se formaron en los círculos aviñoneses. Incluso algunos cortesanos célebres participaron de aquel espíritu renovador, como el canciller Ayala, que desarrolló en sus últimos años de vida un patrocinio muy notable en el monasterio alavés de Quejana ${ }^{13}$.

El rey promovió la reforma usando los medios que tenía a su alcance. Las disposiciones adoptadas en las Cortes de Palencia de 1388 trazaron las normas generales para impulsar la renovación de las costumbres, formación, disciplina y modos de vida del estamento clerical bajo la acción del legado papal Pedro de Luna ${ }^{14}$. En lo tocante a la vida monástica se buscaba el modo de revitalizar antiguos cenobios que arrastraban una larga decadencia y, sobre todo, de instituir modelos de renovación espiritual capaces de influir en el panorama general de la vida consagrada. A través de esta vía nacieron los mental.

9 G.M. Colombás, M.M. Gost, Estudios; los textos fundacionales en el apéndice docu-

10 L. Suárez Fernández, Reflexiones en torno a la fundación de san Benito; idem, Historia del reinado de Juan I, pp. 351-372.

11 J. García Oro, Cisneros y la reforma del clero, pp. 245-247; J.M. Nieto Soria, Franciscanos y franciscanismo. Un apunte biográfico todavía útil es el de A. López Fernández, Fray Fernando de Illescas, pp. 241-252.

12 R. Sánchez Sesa, Don Pedro Tenorio.

13 E. García Fernández (coord.), La Tierra de Ayala.

14 J. Zunzunegui, La legación en España. 
primeros monasterios de jerónimos ${ }^{15}$ y $\operatorname{cartujos}^{16} \mathrm{y}$, naturalmente, el de san Benito el Real de Valladolid. Este panorama es lo bastante conocido como para insistir más en él ${ }^{17}$.

Hay un detalle que siempre ha llamado la atención de los especialistas: la proximidad cronológica entre las tres fundaciones más señaladas de Juan I, es decir, Guadalupe (desde que es encomendado a los jerónimos en 1389), santa María de El Paular (primera cartuja castellana) y el propio san Benito de Valladolid, ambas en 1390. Los tres se crearon en el lapso de un año, entre los veranos de 1389 y 1390 , y tienen en común un detalle tal vez anecdótico: que sus respectivos nacimientos fueron promovidos durante las estancias veraniegas de Juan I en el monasterio cisterciense de santa María de la Sierra, cerca de Sotosalbos, en la sierra segoviana. Pero más allá de la anécdota subyace una cuestión de fondo que es preciso considerar: me refiero a la evolución del pensamiento del propio rey en todo lo relacionado con la protección dispensada a los monasterios de sus reinos y, más concretamente, a los benedictinos.

Juan I buscó la manera de mejorar las condiciones de subsistencia material de las comunidades monásticas al constatar que una parte del problema de esa decadencia a la que antes aludíamos residía precisamente en este punto, en los soportes económicos que hacían posible su existencia. Ya en las Cortes de Soria de 1380 había decidido la supresión de las encomiendas laicas que pesaban sobre numerosos monasterios del norte de sus reinos, especialmente en Galicia, Asturias, León y Castilla la Vieja ${ }^{18}$. Se trataba de un viejo problema que venía causando notables perjuicios a los benedictinos, sobre todo desde el reinado de Fernando IV. El rey definió los casos en que eran legítimas las encomiendas, prohibiendo las que no se ceñían a la norma -que eran la mayoría-, y además creó una comisión judicial de cuatro magistrados para dictaminar con urgencia la validez o nulidad de las reclamaciones presentadas por los abades y priores ${ }^{19}$. La justicia real acabó dando la razón a la mayoría de los monasterios que presentaron sus quejas. Algunos de los miem-

15 M.Á. Ladero Quesada, Mecenazgo real y nobiliario; J. Sánchez Herrero, Fundación y desarrollo.

16 S. Cantera Montenegro, Los cartujos: idem, Las relaciones de las cartujas.

17 Una buena visión sobre el sentido de las reformas en J.M. Revuelta Somalo, Renovación de la vida espiritual, pp. 189-224.

18 L. Suárez Fernández, Historia del reinado de Juan I, I, pp. 46-49 y 59-63.

19 Los jueces nombrados por el rey fueron Pedro López de Ayala, Juan Martínez de Rojas, Pedro Fernández de Burgos y Alvar Martínez de Villarreal; estos dos últimos eran oidores; L. Suárez Fernández, Historia del reinado de Juan I, I, pp. 60-61. 
bros más encumbrados de la nobleza cortesana ${ }^{20}$ sufrieron los efectos de unas sentencias que se dictaron en diciembre de 1380. Sin embargo no parece que aquella solución fuese suficiente, incluso en tiempos del propio Juan I, ya que en las últimas Cortes del reinado -las de Guadalajara en 1390- se volvieron a promulgar nuevas normas para eliminar de raíz las encomiendas laicas: era una señal de que las anteriores sentencias no habían resuelto el problema ${ }^{21}$. La cuestión quedará pendiente de solución a lo largo de los restantes reinados ${ }^{22}$.

La insuficiencia de la vía judicial parece estar relacionada, al menos en parte, con la cuestión de conciencia escrupulosa que manifestó públicamente Juan I a raíz del desastre militar de Aljubarrota en 1385. Tratando de encontrar una respuesta coherente a los motivos profundos de la derrota, el rey afirmó ante las Cortes de Valladolid de ese mismo año que el revés respondía en el fondo a un juicio divino, a un castigo merecido tanto por los pecados del propio rey como de sus súbditos, especialmente de los poderosos que habían actuado de manera abusiva desde los comienzos del reinado ${ }^{23}$. Juan I asumía la parte de culpa que le correspondía al no haber atajado el problema: se arrepentía de haber tolerado la injusticia de forma continuada. Era preciso enmendar el yerro y recobrar el favor divino para intentar de nuevo la recuperación de Portugal ${ }^{24}$. Llegados a este punto cabe plantearse si el rey tuvo en cuenta este propósito de enmienda a la hora de promover la fundación de los tres monasterios ya citados (Guadalupe, El Paular, san Benito de Valladolid), y muy especialmente el de san Benito, ya que algunos de los poderosos que más se habían distinguido en el comportamiento injusto eran precisamente aquellos que habían usurpado las propiedades y derechos de los monasterios benedictinos mediante las encomiendas. Esta hipótesis no tendría la suficiente entidad de no ser por la presencia de algunos indicios que apuntan en esta dirección, al menos por lo que se refiere a la fundación de san Benito el Real.

El primer argumento tiene que ver con la cronología fundacional de las tres comunidades observantes: no sólo son muy cercanas en el tiempo sino que se producen cuando el rey planeaba una nueva estrategia para recuperar Portugal. El segundo indicio está relacionado con los textos primitivos de san

20 El profesor Suárez publica o resume 22 sentencias en el apéndice de su estudio sobre el reinado de Juan I. Entre los magnates perjudicados figuran Fadrique Enríquez, duque de Benavente; Alfonso Enríquez, conde de de Noreña; Pedro Fernández de Velasco, camarero mayor; Pedro Enríquez, conde de Trastámara y Lemos; Pedro Ruiz Sarmiento, adelantado mayor de Galicia. L. Suárez Fernández, Historia del reinado de Juan I, I, II, passim.

21 En el Ordenamiento de prelados se alude a la situación de Galicia, donde muchos laicos seguían usurpando bienes eclesiásticos; Cortes, II, pp. 449-459.

22 J.L. Santos Díez, La encomienda de monasterios; M. Diago, La tutela nobiliaria.

23 Cortes, II, pp. 330-332.

24 C. Olivera, La memoria de Aljubarrota, pp. 277-294. 
Benito el Real, donde se exponen los motivos del monarca al auspiciar el cenobio. El tercero se refiere a la presencia de portugueses exiliados en el entorno del propio monasterio vallisoletano. Veámoslo por partes.

\section{LA CUESTIÓN DE LAS FECHAS FUNDACIONALES}

Las tres fundaciones son, como decíamos, casi contemporáneas. Hay que admitir la posibilidad de una mera coincidencia cronológica o, tal vez, de un anhelo por ver culminados antiguos proyectos fundacionales tras resolver los agobios bélicos. En este sentido hay que reconocer una mejoría parcial de las circunstancias políticas en torno a 1388. La firma del tratado de Bayona con el duque de Láncaster en ese año había resuelto la reclamación dinástica de los petristas y en 1389 se había asentado un régimen de treguas con ingleses y portugueses que permitía prever un cierto respiro de seis años. La relativa calma que se oteaba en el horizonte inmediato tras unos años infernales de guerras, epidemias y reveses de todo tipo hacía viable un plan de fundaciones monásticas, sabiendo que después de la tregua se tendría que reactivar de algún modo o de otro la actividad militar con el fin de recuperar el terreno perdido. El sentido general de tales fundaciones observantes parece indicar que Juan I tenía en mente una idea clara del significado impetratorio y reparador que iban a tener en relación con sus planes políticos.

En el verano de 1389, durante las Cortes de Segovia, Juan I entregó a los jerónimos el santuario de Guadalupe, el más célebre de todos los centros de peregrinación mariana de sus reinos. El significado que para castellanos y portugueses había tenido la protección mariana en la lucha contra los benimerines, especialmente en la batalla de El Salado, era un valor compartido que ahora podría tener cierta utilidad en aras de una reconciliación. La corona portuguesa había hecho ofrendas en el pasado que aún eran visibles en el inventario de bienes que se hizo en el momento del traspaso a los jerónimos ${ }^{25}$. El propio Juan I había acudido en peregrinación en el verano de 1382 y en la primavera de 1383 , justo antes de contraer matrimonio con la heredera de Portugal $^{26}$. El antiguo priorato que había regido los destinos del santuario estaba en ese momento en manos de Juan Serrano, uno de los colaboradores más cercanos del monarca; el fiel consejero real cumplió las instrucciones de

25 Entre las casullas y ornamentos de tela figuran varias piezas con las quinas de Portugal, y en algún caso se cita algún que otro obsequio de monarcas portugueses, como la lámpara regalada por Fernando I; M.F. Cerro, Documentación del monasterio de Guadalupe, doc. 164.

26 L. Suárez, Historia del reinado de Juan I, I, pp. 398-399. 
su señor entregando el templo a los nuevos propietarios ${ }^{27}$. De este modo Guadalupe pasó a ser el segundo monasterio de jerónimos en Castilla después de san Bartolomé de Lupiana. La donación de Juan I está fechada en Sotosalbos el 15 de agosto de 1389, justo cuatro años después de Aljubarrota ${ }^{28}$, aunque la entrada oficial de los monjes se produjo el 22 de octubre.

No parece que el amargo recuerdo de la festividad de la Asunción, tan recargada de luto para los castellanos, modificase la confianza del rey en el amparo de la Virgen, sino más bien lo contrario. En la enumeración de las intenciones que justifican la donación, Juan I menciona la grande esperança que tiene en Jesucristo y su madre, la qual tenemos por abogada en todos nuestros fechos. A renglón seguido solicita las oraciones de los jerónimos en beneficio de sus antepasados, empezando por su abuelo (Alfonso XI), siguiendo por su padre (Enrique II) y sus esposas (Leonor de Aragón y Beatriz de Portugal), concluyendo por los hijos del primer matrimonio (el príncipe Enrique y el infante Fernando). También hace mención de los grandes miraglos que Dios por el su regno muestra e faze cada día en la iglesia que dizen Guadalupe, reconociendo la presencia divina en aquel lugar sagrado tan vinculado a la monarquía.

Poco tiempo después -el 28 de diciembre de 1389- Clemente VII concedía su permiso para fundar el monasterio de san Benito de Valladolid. La bula papal fue la respuesta a una previa demanda del rey que debió de producirse en fechas próximas a la entrega de Guadalupe a los jerónimos y a las gestiones para erigir la primera cartuja castellana, la de El Paular. En suma, se constata que el segundo semestre de 1389 fue particularmente intenso en todo lo relacionado con los proyectos monásticos del rey.

En aquel verano Juan I estaba firmemente decidido a reintentar la recuperación de la corona de Portugal que pertenecía a su mujer, la reina Beatriz $^{29}$. Sabemos por la crónica de Ayala que poco después de entregar Guadalupe a los jerónimos, ya a comienzos de 1390, el monarca presentó ante los miembros de su Consejo un arriesgado plan para expulsar al maestre de Avís. La idea expuesta ante sus atónitos consejeros consistía en renunciar a la corona castellana en favor de su hijo y heredero, el príncipe Enrique, a pesar de su corta edad, para así ceñir en exclusiva la corona portuguesa en compañía de

27 P. López de Ayala, Crónica de Juan I, cap. IV de 1389, p. 124. Los documentos del traspaso en M.F. Cerro, Documentación, docs. 160 y ss.

${ }_{28}$ El rey ordenó la entrega del templo a fray Fernando Yañez de Figueroa y a los frailes de la primera comunidad, junto con el señorío de Guadalupe. Pedro Tenorio, arzobispo de Toledo, otorgó su consentimiento el 1 de septiembre de 1389 y autorizó al prior Juan Serrano para entregar el santuario a los jerónimos. El día 20 de septiembre Juan I informó de su decisión al concejo de Guadalupe. I. de Madrid, Los monasterios, pp. 114-116.

29 C. Olivera, Beatriz de Portugal, pp. 106-108. 
su mujer. De este modo pretendía demostrar a sus rebeldes súbditos lusitanos que no iba a producirse la tan temida anexión a Castilla. Como complemento a tan original idea, el rey pretendía conservar una parte de las rentas castellanas con las que financiar la operación. Tras un intenso debate con sus hombres de confianza el plan fue finalmente rechazado tras considerar con detenimiento los graves riesgos que acarreaba ${ }^{30}$.

En este frustrado proyecto se observa un modelo de comportamiento bastante novedoso destinado a desarmar la hostilidad de los portugueses con una puesta en escena muy audaz. El rey quería presentarse ante todo como monarca pacífico y humilde, capaz de despojarse de su propia corona con el fin de tranquilizar a los rebeldes que se habían unido bajo el liderazgo del maestre de Avís en defensa de la independencia portuguesa. Esta imagen poco o nada tenía que ver con la impresión brutal de rey invasor y autoritario que pudieron ver sus enemigos, cuando la ocupación militar castellana de Portugal le hizo aparecer como un tirano. Lo más llamativo de esta nueva estrategia era que parecía dar una parte de la razón a su rival, ya que un cambio de rumbo tan pronunciado implicaba el reconocimiento tácito de los errores fatales cometidos en el pasado reciente. No era del todo extraño que la justicia divina hubiese dejado caer su pesado brazo sobre las huestes castellanas hasta pulverizarlas. Quienes sí habían sabido aprovechar a la perfección el juicio divino eran los leales del maestre de Avís. Pronto diseñarán una explicación providencialista mediante la cual João I será presentado como un nuevo Mesías de Lisboa -la expresión es de Margarida Garcez Ventura ${ }^{31}$ - capaz de acaudillar por el desierto de la tribulación a su pueblo y liberarlo de las garras del faraón castellano. Juan I debió de comprender el alcance de sus errores anteriores y buscó una imagen totalmente nueva capaz de alterar la percepción que los portugueses tenían de él. Encontró una fórmula de matriz religiosa, la del rey humilde que se desprende de su estado, a semejanza de Jesucristo, que no hizo alarde de su condición, sino que se despojó de su rango, tal y como se lee en Filipenses 2, 6.

Una vez desechado este plan "pacifista" por inviable y hasta peligroso, Juan I declaró ante las Cortes de Guadalajara que, pese a todo, mantenía el propósito de reanudar la guerra con Portugal: fiaba en Dios, que pasado el tiempo de la tregua, él tornaría a la guerra como cumplía a su servicio, e en tanto que los suyos descansarían ${ }^{32}$. Reiteró su deseo de dar batalla a los de Portogal e

30 P. López de Ayala, Crónica de Juan I, cap. I de 1390.

31 M. Garcez Ventura, O Messias de Lisboa. La expresión es una especie de traslado de la imagen bíblica de Cristo y la Jerusalén celestial, ya que el maestre y Lisboa encarnan ese designio.

32 P. López de Ayala, Crónica de Juan I, cap. III de 1390.

ANUARIO DE Estudios Medievales, 43/2, julio-diciembre 2013, pp. 799-832 ISSN 0066-5061, doi:10.3989/aem.2013.43.2.11 
ponerlo en el juicio e voluntad de Dios e non dexar este fecho así olvidado, con tan grand deshonra como Castilla avía rescebido ${ }^{33}$. Las treguas tenían una duración prevista de seis años y en ese lapso de tiempo habría que hacer acopio de recursos económicos y humanos para volver a la carga en 1396.

Es muy llamativa la reiterada alusión al juicio de Dios en todo lo relacionado con su reclamación dinástica. Y lo es más teniendo en cuenta que ya había apelado a este supremo argumento en los instantes inmediatamente anteriores a la batalla de Aljubarrota. Juan I nunca consideró como definitiva la sentencia divina que padecieron los castellanos en la aciaga tarde del catorce de agosto de 1385, cuando lo más selecto de su ejército perdió la vida en el campo de san Jorge ante el maestre de Avís y el condestable Nuno Alvares Pereira. A tenor de lo visto hasta aquí cabe preguntarse si el rey pensaba en las nuevas fundaciones monásticas como un elemento más de los restantes preparativos, es decir, como una plegaria impetratoria del favor divino en vísperas de una nueva guerra que iba a restaurar la honra perdida de sus reinos.

En julio de 1390 Juan I volvió a escoger el monasterio de Sotosalbos como residencia veraniega, buscando el frescor de la sierra segoviana. Muchos de sus actos en aquellas semanas están empapados de significados religiosos. Ayala nos cuenta en su crónica un detalle revelador del día 25, fiesta de Santiago Apóstol, una fecha importante para recabar el patronazgo celestial tanto para la monarquía como para la caballería en vísperas de una nueva guerra. El rey acudió a la catedral de Segovia para instituir pública y solemnemente una nueva divisa personal, el collar de la paloma, para aquellos caballeros que cumpliesen con ciertos requisitos:

que él avía ordenado de traer una devisa, la cual luego mostró allí, que era como un collar fecho como rayos de sol, e estaba en el dicho collar una paloma blanca, que era representación de la gracia del Espíritu Santo, e mostró un libro de ciertas condiciones que avía de aver el que aquel collar troxiese; e tomó el rey aquel collar de sobre el altar, e dióle a ciertos caballeros suyos ${ }^{34}$

En la misma ceremonia creó otra divisa, la de la Rosa, para los escuderos de sus reinos y para los que querían provar los cuerpos justando o en otra manera ${ }^{35}$. No parece que tratase de postergar la Orden de la Banda de Alfonso XI, sino de ampliar el repertorio con dos divisas de claro contenido

33 Ibidem, cap. V de 1390.

34 Ibidem, cap. XVIII de 1390.

35 Ibidem. En reediciones posteriores de la crónica se introduce una variación errónea del nombre, divisa "de la razón"; véase J. Pérez de Guzmán y Gallo, Memoria sobre la Orden de la Banda, p. 461. 
religioso para galardonar a caballeros, escuderos y justadores. Da la impresión de que Juan I buscaba un tipo de caballero cristiano no vinculado al régimen de vida de las órdenes militares aunque sí especialmente unido a la corona, con una exaltación de virtudes castrenses y espirituales que no podemos precisar a falta de datos. En este punto es lógico plantearse como hipótesis si pudo haber algún tipo de relación entre estas dos divisas con la Orden de la Jarra y el Grifo que creará en 1403 el segundo hijo de Juan I, el infante don Fernando, sobre todo teniendo en cuenta la estrecha relación afectiva entre padre e hijo. Por desgracia no podemos saberlo puesto que, como reconoce Ayala, las divisas de Juan I desaparecieron con la muerte del rey.

Lo que sí resulta llamativo es que la crónica del canciller sitúe a continuación la fundación de la primera cartuja castellana, la de El Paular, dando a entender de algún modo la existencia de un nexo de unión entre ambos acontecimientos ${ }^{36}$, aunque sólo sea el espíritu de devoción que embargaba al rey en aquel verano tan plagado de nuevas fundaciones ${ }^{37}$.

No se conservan los textos originales de la primera cartuja castellana, erigida el 29 de agosto de 1390, pero contamos con otros documentos coetáneos que revelan las intenciones de Juan I, como la carta que el rey dirigió al prior general de los cartujos dando cuenta de la fundación ${ }^{38}$. Como motivos generales el rey señala el prestigio de la orden cartujana, el culto a la gloria divina y la exaltación del nombre de Dios; y como motivos más concretos incluye el servicio de Dios, su profundo aprecio por los cartujos y el cumplimiento de un deseo personal (nostrum propositum finem veniat ad optatum) ${ }^{39}$. Esta última expresión, un tanto enigmática, dio pie a la leyenda difundida por los propios cartujos en tiempos de Enrique III, según la cual Juan I habría erigido El Paular para reparar la ofensa cometida por Enrique II cuando destruyó en Francia dos monasterios, uno de ellos cartujo, durante su exilio. No hay pruebas que demuestren la veracidad de tal aserto, pero en la tradición de El Paular quedó firmemente asentado este convencimiento. Esta misma leyenda acabará pasando a la tradición de san Benito el Real de Valladolid en el siglo XVI ${ }^{40}$.

36 Sobre el sentido de estas divisas véase J.D. Rodríguez Velasco, El debate sobre la caballería, p. 35 .

37 Algunos historiadores antiguos de la orden cartujana aseguran que Juan I prometió en este día, el 25 de julio de 1390, iniciar en tres meses las obras de la primera cartuja; I.M. Gómez, El Paular y san Benito, p. 41. Tal vez se trate de una tradición posterior similar a la del supuesto desagravio que Juan I quiso acometer por los desmanes de su padre en Francia.

38 Fechada el 12 de septiembre de 1390. Analiza con detalle esta cuestión I.M. Gómez, El Paular, pp. 5-44, a quien seguimos en sus observaciones.

39 Ibidem, p. 37.

40 Según la tradición de san Benito, Juan I quiso reparar la destrucción de un monasterio benedictino que cometió Enrique II. La leyenda figura en el encabezamiento del Libro de bienhechores editado por G.M. Colombás. 


\section{Los textos Fundacionales de SAN Benito El ReAl DE VAlladolid}

Y llegamos por fin al nacimiento del cenobio vallisoletano, que también vio la luz al final de aquel verano tan especial de 1390 en el que Juan I culminó su plan de fundaciones. Clemente VII había concedido la preceptiva autorización a fines de 1389 para fundar un monasterio benedictino, respondiendo a una demanda previa del propio rey, de modo que en los meses que transcurren desde la primera petición hasta su aparición definitiva se sucede un tiempo aprovechado para encontrar las personas idóneas y el emplazamiento ${ }^{41}$. Conviene recordar una vez más que la idea se gestó cuando el monarca aún sopesaba la posibilidad de recuperar Portugal como rey pacífico.

Sorprende que la crónica de Ayala no cite el nacimiento de san Benito el Real, aunque es posible que el cronista no tuviese una razón especial para relatar su fundación; quizás la consideró poco relevante. Los historiadores antiguos del monasterio, en cambio, ofrecen una versión diferente: el comienzo de la andadura fue problemático debido a la indefinición jurídica que sobrevino tras la temprana muerte del rey, a comienzos de octubre. El texto fundacional que se redactó en Turégano el 21 de septiembre de 1390 tuvo una laguna legal para su plena validez canónica, la dispensa pontificia, que se retrasó más de la cuenta. También hubo problemas con la dotación económica y con la asignación de espacios en el interior del alcázar. Estas dificultades, según los historiadores benedictinos, estuvieron a punto de provocar el fracaso de la nueva casa, aunque los monjes fueron capaces de superar todas las adversidades con notable heroísmo.

Pasemos primero a observar el contenido del texto fundacional. La exposición de motivos realizada por Juan I es una demostración patente de sus creencias personales ${ }^{42}$, del mismo modo que lo son El Paular y Guadalupe. La nueva casa de oración se levanta como muestra de su agradecimiento por las mercedes divinas que ha recibido y recibe cada día, non por los nuestros mereçimientos, mas por su grande misericordia e piedat. Es notable que el rey apele a la misericordia divina y no a la justicia, sabiendo que le esperaba un juicio divino ante Portugal. En el segundo motivo hay una velada alusión al calvario de penalidades que había padecido en los años anteriores: el rey desea faser thesoro en los çielos, el qual dura por siempre sin peligro alguno a plaser e a gloria de aquel que lo fase, mudando los bienes corrutibles e temporales en los bienes perdurables e çelestiales. Juan I no había tenido ni el más mínimo placer o gloria en los trágicos sucesos del pasado, por no

41 Bula de Clemente VII fechada en Aviñón el 28 de diciembre de 1389; G.M. Colombás, M.M. Gost, Estudios, Apéndice I.

42 I.M. Gómez, El Paular y san Benito, p. 35. 
hablar de los agobios económicos -bienes corruptibles- que recaían sobre sus espaldas y de sus súbditos, de modo que la frase puede dar cierta idea de los anhelos más sentidos del atribulado monarca.

El relato prosigue con otro motivo que tienen en común los tres centros fundados por él: que el nombre de Dios, el de su santa madre y el de los santos sea servido e loado como conviene, para lo cual se funda un monasterio de monjes prietos de la Orden de san Benito. La invocación a los supremos nombres de la corte celestial puede tener una justificación genérica que sería común a la de cualquier casa de oración de la época, pero sabemos por otras fuentes que la intención de reunir unos "monjes prietos" de estricta observancia con una clausura similar a la de las clarisas era una reconocimiento expreso de que los monasterios benedictinos de la corona de Castilla no estaban viviendo en ese momento tal régimen de vida. Otro tanto podría decirse del resto de monasterios masculinos de diferentes obediencias. El único caso verdaderamente ejemplar era el de las hijas de santa Clara. Aunque el rey no lo afirme expresamente, se deduce que el modelo a imitar era el convento reformado de Tordesillas que ya llevaba una década de existencia bajo el gobierno de fray Fernando de Illescas.

En el último de los motivos encontramos indicios que nos conducen a sus proyectos políticos inmediatos:

Los dichos monjes que en el dicho menesterio fueren de presente e fueren dende en adelante por sienpre rueguen a Dios por la nuestra salud e por la nuestra vida e de los otros reyes que de nos vinieren, porque governemos e rijamos los regnos que por él nos son acomendados, al su santo serviçio e a salvaçión de la nuestra alma ${ }^{43}$.

En este párrafo se encadenan varias cuestiones complementarias, como la maltrecha salud del rey, que ya había estado a punto de costarle la vida en el caluroso verano de 1385 . Después aparece la oración en favor de sí mismo y de los futuros reyes tratando de asegurar una plegaria litúrgica constante en favor de la monarquía para que sus sucesores sean buenos gobernantes. Hasta aquí todo parece transcurrir dentro de los cauces habituales en una fundación regia. Ahora bien, es preciso tener en cuenta un detalle crucial: que Juan I se sigue intitulando en ese momento rey de Castilla, León y Portugal, algo que se comprueba con facilidad tanto en los documentos de su cancillería como en la de su mujer, de modo que una alusión al buen gobierno de sus reinos -de todos ellos sin excepción- llevaba aparejada la recuperación de

\footnotetext{
43 Ibidem.
}

ANUARIO de Estudios MEdievales, 43/2, julio-diciembre 2013, pp. 799-832 ISSN 0066-5061, doi:10.3989/aem.2013.43.2.11 
aquellos que aún no estaban bajo su autoridad. Aquí podemos percibir un eco del propósito de enmienda manifestado ante las Cortes de Valladolid de 1385, cuando expuso las causas profundas de la derrota y citó la injusticia tolerada por él mismo ante los poderosos de sus reinos, algo que se tendría que corregir si se pretendía recuperar el favor de la justicia divina. La oración de los monjes para conseguir un buen gobierno y dar cuenta a Dios de los reinos que le habían sido encomendados iba en la línea de lo prometido a sus súbditos.

En las fundaciones de Guadalupe y El Paular no se alude al conjunto de los reinos ni referencias al buen gobierno. En san Benito el Real, en cambio, resalta con nitidez esta novedad. Si en Guadalupe hay una mención a la familia real (incluyendo a los antepasados) y en El Paular se habla de un viejo proyecto del rey finalmente cumplido (la expansión de la Cartuja), en san Benito se hace una velada insinuación al principal problema político que Juan I tenía planteado para el futuro inmediato. Es cierto que no aparecen alusiones claras y explícitas al problema de Portugal, al menos tal y como se había hecho ante las Cortes, pero el contexto pone de relieve el significado que tendrían estas fundaciones para Juan I.

El trasfondo político lusitano también puede advertirse en el primitivo sello del monasterio. Por suerte se conserva una descripción que debemos a fray Mancio de Torres ${ }^{44}$. El motivo iconográfico principal no era san Benito, como hubiese sido lógico, sino la Virgen María rodeada de los doce apóstoles, que es su asunçión y tránsito. Encima de la imagen aparecía un escudo sostenido por dos ángeles con las armas de Castilla, León y Portugal, es decir, las armas de Juan I y doña Beatriz. La razón que aporta fray Mancio para explicar la presencia eminente de la Virgen en el sello se debe a la especial devoción que le manifestaron los monjes tras la muerte de Juan I, ya que en las dificultades que sufrieron siempre se sintieron protegidos por su intercesión. Los benedictinos no pudieron cambiar la advocación del monasterio, como hubiese sido su deseo, puesto que el patronazgo de san Benito había sido decidido por el rey fundador, pero al menos consiguieron poner a santa María en el cuerpo principal del sello y más adelante le dedicaron la primera fundación nacida de la comunidad vallisoletana, el monasterio de santa María de la Consolación de Calabazanos ${ }^{45}$.

Encontramos otros indicios que corroboran la estrecha vinculación de san Benito el Real con los proyectos lusitanos de Juan I. Veamos por ejemplo la primitiva fisonomía del cenobio.

44 El sello de cera blanca pendía del documento de la elección canónica del segundo prior, fray Juan de Madrigal, elegido el 10 de marzo de 1399; BSCV, leg. 195, ff. 72-74.

45 La fundación del monasterio de la Consolación de Calabazanos en 1431 fue posible gracias al adelantado de León Pedro Manrique y su mujer, Sancha de Rojas, muy devotos de la Virgen; BSCV, leg. 195, f. 145r. 


\section{UN ENCLAVE ATÍPICO}

Una cuestión relevante es la elección misma de Valladolid. En este punto conviene advertir que la villa pertenecía en ese momento al señorío de su mujer. La reina Beatriz lo venía ejerciendo al menos desde 1388 y lo conservará hasta 1405 . En años posteriores, ya durante la minoría de Juan II, la reina aparecerá por la villa en algunas ocasiones, incluso en fechas bastante tardías ${ }^{46}$, aunque ignoramos en dónde se alojaba. Cuando se elabore el lujoso Libro de los bienhechores, su nombre aparecerá consignado entre los miembros de la realeza que dejaron su huella en la historia del monasterio.

Juan I era consciente del valor jurídico y simbólico de su mujer para justificar la recuperación de Portugal y para aglutinar el exilio portugués en Castilla $^{47}$. Por su parte la reina facilitó la instalación de un número considerable de compatriotas en las villas de su señorío, y Valladolid no fue una excepción. Algunos oficios públicos locales, como el de escribano, llegarán a tales niveles de saturación en 1397 que será necesario limitar su número ${ }^{48}$. El patrocinio de la reina sobre otros monasterios vallisoletanos, como la Merced o san Pablo, también será notorio. Por otra parte algunos de sus consejeros eclesiásticos intervendrán en la iglesia de la villa, como su capellán mayor Pedro de Fonseca, cardenal de sant'Angelo, que será abad de Valladolid, mientras que en la colegiata se acogerán algunos clérigos exiliados.

Aquí estaría, por tanto, una posible razón para justificar la elección de Valladolid. Estamos ante un núcleo urbano de realengo con una apreciable presencia de exiliados que se acogen a la protección regia. Este grupo lusitano tenderá a desaparecer paulatinamente cuando Catalina de Láncaster se convierta en la nueva señora de la villa a partir de 1406, pero la evolución posterior del tejido social urbano no anula el hecho anterior.

En cuanto al emplazamiento del nuevo monasterio, la decisión parece algo sorprendente, ya que Juan I instaló a los benedictinos en el alcazarejo de Valladolid, situado a escasa distancia del alcázar principal, que era una de las sedes que utilizaba el rey cuando se alojaba en la villa ${ }^{49}$. Junto a estos dos núcleos fortificados, que estaban unidos entre sí, se desplegaba hacia el río Pisuerga un conjunto de casas y huertas que formaban el barrio de Rehoyo ${ }^{50}$.

46 La reina manifiesta su intención en el año 1418 de viajar a Valladolid o a Toro; F. de P. Cañas, Colección diplomática, doc. 135.

47 C. Olivera, Beatriz de Portugal, pp. 209-210.

48 Juana Manuel, la anterior señora de Valladolid, también había nombrado numerosos escribanos; A. Rucquoi, Valladolid en la Edad Media, II, pp. 150-159.

49 Las fases de la construcción del monasterio en M. Martín Montes, El Alcázar; A. Bustamante, San Benito el Real, pp. 133-148.

50 Un plano ilustrativo de su localización en M. Martín Montes, El Alcázar, p. 235. 
Parece que la idea original del rey era instalar en el alcázar principal la primera comunidad -se había previsto una cifra de dieciocho monjes-, aunque para empezar la vida conventual se tuvo que aprovechar temporalmente el alcazarejo. Una vez terminadas las obras del alcázar mayor, los monjes dejarían de habitar el pequeño alcazarejo, aunque éste quedaría incluido dentro del conjunto monástico.

Al margen de que esa unidad fortificada del alcázar y alcazarejo tuviese malas condiciones de habitabilidad - cosa que afirman con ahínco los cronistas de san Benito de época moderna-, o de que fuese un edificio poco apropiado para un uso conventual, por provisional que fuese, es preciso reconocer que no era frecuente encontrar un monasterio benedictino dentro de un marco urbano y, menos aún, en un enclave militar y palaciego. Si lo que se buscaba era un ambiente de oración totalmente apartado del mundo exterior, no parece que la elección fuese demasiado acertada, a no ser que las intenciones de Juan I consistiesen precisamente en tener muy cerca a los monjes de clausura que iban a orar por él y por sus reinos. Esta pudo ser, por lo que parece, la intención del rey.

El minucioso estudio del alcázar vallisoletano realizado por Martín Montes revela que desde su fundación en 1390 hasta mediados del siglo XVI hubo unas "salas reales" y unos "palacios" adosados al convento de clausura, aunque no siempre estuvieron en el mismo lugar ${ }^{51}$. Estas estancias reservadas para el rey y su familia desaparecerán a partir de las grandes reformas arquitectónicas de la época de Felipe II. En esta distribución se observa un paralelismo con otros palacios-monasterios coetáneos ${ }^{52}$, como el convento de santa Clara de Tordesillas, donde también coexistían dos espacios yuxtapuestos: por una parte estaba el antiguo palacio real de la primera mitad del siglo XIV y por otro el ámbito reservado para la comunidad de monjas ${ }^{53}$. Los dos cenobios podrían guardar una relación más estrecha de lo que se pensaba hasta ahora ya que la reina Beatriz de Portugal, además de ser señora de Valladolid, lo fue también de Tordesillas entre 1383 y $1389^{54}$. Sin embargo se pueden dar otras explicaciones para entender el uso de espacios paralelos. En la misma Valladolid había precedentes anteriores, como el palacio de la Magdalena, que María de Molina donó a las monjas cistercienses para levantar el monasterio de Las Huelgas ${ }^{55}$.

51 M. Martín Montes, J. Moreda Blanco, Los 'Palacios' de san Benito, pp. 931-938.

52 F. Chueca, Casas reales.

53 Los estudios más recientes sobre el palacio de Tordesillas son los de J.C. Ruiz Souza, Santa Clara de Tordesillas: nuevos, pp. 32-40; idem, Santa Clara de Tordesillas, en Los Reales Sitios, vol. 6, Real Monasterio de santa Clara de Tordesillas, pp. 19-27.

54 J. Castro Toledo, Colección diplomática de Tordesillas, doc. 223, 236 y 277.

55 A. García Flores; J.C. Ruiz Souza, El palacio de María de Molina, pp. 2-13. 
Conocemos con cierto detalle la localización de las estancias reales en el interior de san Benito el Real gracias a una provisión de Juan II de 1432 regulando el modo de proceder cuando el rey y sus acompañantes entraban dentro de la clausura ${ }^{56}$. La ordenanza fue la respuesta a una demanda previa presentada por el prior Juan de Acevedo, que se sentía molesto por la alteración de la vida conventual siempre que llegaban el monarca y los suyos. No sabemos si tales inconvenientes ya se daban en épocas anteriores -cosa probable- o si se debían a Juan II. Sea como fuere, el documento delimita con precisión los ámbitos religioso y cortesano. Había en realidad dos estancias regias diferentes. Se localizaba un primer palacio junto a la entrada principal que daba al río Esgueva; esta estancia regia estaba separada del núcleo principal de la clausura, de modo que la entrada del monarca con su séquito no perturbaba excesivamente la vida cotidiana de la comunidad. El otro palacio, en cambio, se localizaba junto al segundo corral del alcázar y estaba totalmente rodeado por las estancias que usaban los monjes, provocando la lógica intromisión si al monarca se le ocurría entrar o, como dice la provisión, si deseaba presenciar el oficio de sus capellanes. Este último detalle es importante porque atestigua la supervivencia de la capilla real en el interior del monasterio, algo que ya se había dado en los tiempos de Juan I. No sabemos si la actividad litúrgica de los capellanes reales era intermitente o continua, o si dependía de las estancias temporales del rey en la villa, pero no por ello dejaba de interferir en el normal desarrollo de la vida claustral. A esta realidad habría que añadir la presencia continuada del capellán real que actuaba de forma permanente desde los primeros tiempos del monasterio con el fin de implorar por el rey, sus intenciones y sus reinos.

La provisión de 1432 sobre la clausura nos informa de otros aspectos que tienen que ver con la reina. Aunque la presencia femenina nunca fue permitida, salvo en el espacio reservado a la iglesia, se insiste en que ninguna mujer, o reina o otra señora poderosa entre dentro de la clausura, ni que el prior o los monjes sean apremiados por causa ni razón alguna a las acoger, dejando en el aire la duda acerca del cumplimiento anterior de esta norma, lo cual nos lleva de nuevo al papel desempeñado por la reina Beatriz en los comienzos del monasterio.

La documentación antigua de san Benito atestigua la huella de la reina portuguesa en los asuntos cotidianos del recinto fortificado vallisoletano cuando fue transformado en cenobio aunque, eso sí, bajo la autoridad superior de su marido. Sabemos, por ejemplo, que el 30 diciembre de 1388 doña Beatriz donó a García Fernández de Velliza el edificio de los baños desbaratados que estaban junto al alcázar; Juan I confirmó la donación de su mujer el 2 de

56 No se conserva el original de la provisión, fechada en Valladolid el 23 de mayo de 1432, pero fray Mancio de Torres nos ha dejado un amplio resumen de su contenido; BSCV, leg. 195, ff. 133-136.

ANUARIO de Estudios MEdievales, 43/2, julio-diciembre 2013, pp. 799-832 ISSN 0066-5061, doi:10.3989/aem.2013.43.2.11 
agosto de $1389^{57}$, es decir, cuando ya se habían instalado los primeros monjes en el alcazarejo. Este dato demuestra que en las inmediaciones del alcázar se estaban asentando algunos servidores de la reina. No parece que García Fernández tuviese la más mínima relación con las labores de acondicionamiento del alcázar y, de hecho, su presencia acabó siendo un estorbo para los monjes.

Hay un segundo texto que corrobora esta interpretación. Juan I había hecho una donación sólo unos días antes, el 15 de julio de 1389, en favor de su capellán Sancho Martínez ${ }^{58}$, abad de Cabañas, de la huerta de Valladolid detrás del alcaçarejo $o^{59}$ para que la comunidad pudiese alimentarse. Sin embargo el 8 de septiembre los benedictinos ya habían ocupado una parte del alcázar principal, probablemente tras las oportunas reformas, de manera que el alcazarejo y su capilla habían pasado a ser utilizados por los capellanes reales que acudían para el canto litúrgico ${ }^{60}$. El hecho de que monjes y capellanes reales compartiesen espacios tan próximos provocó algunos roces, incluso entre el rey y la reina: sabemos que el monarca ordenó personalmente a García Fernández de Velliza, el subordinado de su mujer, que entregara la llave de los antiguos baños a Sancho Martínez de Cabañas insistiendo en que nyn lo dexedes de faser por carta que digades o tengades de merçed de la rreyna nuestra moger, ca nuestra merçed es que le sea luego entregada la dicha llave al dicho Sancho Martines ${ }^{61}$. La frase demuestra que Sancho Martínez desempeñaba una doble tarea: por una parte era responsable de que la capilla real funcionase correctamente -él mismo era capellán real-y por otro lado hacía las gestiones oportunas para encontrar candidatos suficientes con los que empezar el monasterio de clausura. En suma, que la primitiva comunidad benedictina aún no constituida formalmente coexistía con un ambiente palaciego controlado en parte por la reina, en el que además había que compartir espacios con la capilla real de Juan $\mathrm{I}^{62}$.

57 García Fernández de Velliza era vecino de Valladolid y era hijo de Gonzalo García. La carta de la reina indica que los baños estaban "çerca del alcáçar con las bouedas e huerta e corral e con todas sus entradas e pertenençias como más larga mente se solían usar al tiempo que estavan adobados los dichos baños"; AHN, Clero, carp. 3445, n 4 bis.

58 Sancho Martínez de Cabañas será el encargado de captar monjes observantes en distintos monasterios benedictinos; G.M. Colombás, Estudios, p. 25.

59 Lleva firma autógrafa del rey. AHN, Clero, leg. 7734, s.f.

60 Albalá de Juan I (1389, septiembre, 8, Segovia) mandando a García Fernández de Valladolid, criado del arzobispo de Santiago, que tenga la llave de la puerta de los baños cerca del alcázar y que se la entregue a Sancho Martínez de Cabañas, capellán real, para que pueda entrar y salir a proveer a los monjes que el rey ha mandado instalar en el alcázar, y para que puedan entrar a cantar algunos capellanes que ha mandado poner en la capilla del alcazarejo. AHN, Clero, Leg. 7734, s.f.

${ }_{61}$ Ibidem.

62 La capilla real de san Benito, hoy desaparecida, tenía la advocación de san Ildefonso y serviría como capilla mayor de la iglesia del convento. Su emplazamiento se correspondería con la sacristía actual; D. Nogales, La representación religiosa de la Monarquía. 
Mientras se culminaban las gestiones a finales del verano para que san Benito empezase a funcionar, el rey también se ocupó de ir recuperando algunas parcelas y casas que había en las inmediaciones del alcázar pertenecientes a ciertas personas del entorno real. El 21 de septiembre de 1389, desde Turégano ${ }^{63}$, Juan I comunicaba a los alcaldes y merino de Valladolid que en el pasado reciente había hecho merced a madona Urraca $^{64}$ de una huerta en la villa, cerca de la huerta del nuestro alcáçar; madona Urraca la había vendido a Juan Rodríguez, el cual a su vez había hecho ciertas labores en ella. Para extirpar este incómodo quiste el rey ordenaba a sus oficiales hacer pesquisa sobre su valor para proceder a la expropiación y subsiguiente entrega a los monjes. En este caso se observa de qué modo el rey estaba intentando una remodelación de los espacios inicialmente adjudicados a personajes de su séquito para mejorar las condiciones del monasterio.

Contando con la bula de Clemente VII (de 28 de diciembre de 1389) autorizando la creación de san Benito y con el privilegio de Juan I (dado en Turégano el 21 de septiembre de $1390^{65}$ ) se llevó a cabo la fundación oficial el 27 de septiembre de 1390. El rey no pudo estar presente en el acto. El acta fundacional revela algunos detalles interesantes ${ }^{66}$. Al margen de los motivos devocionales que ya hemos comentado, el texto desvela otros pormenores. La solemne sesión se realizó en la capiella del rey en el alcáçar mayor, con lo cual queda claro que ya existía formalmente una capilla real en el recinto principal y que era diferente a la que primero utilizaron los monjes en el alcazarejo. El monasterio quedaba constituido en todo el dicho alcáçar, es decir, en el conjunto defensivo del alcázar y el alcazarejo. Lo que no dice expresamente el documento -aunque conviene tenerlo en cuenta- es que en el interior del monasterio estaban las estancias reservadas para la familia real. Por este motivo se harán alusiones al uso compartido de espacios en los años venideros.

\section{LA PRIMERA DOTACIÓN ECONÓMICA}

Los estudiosos de la orden y del monasterio siempre han especulado sobre los motivos del retraso evidente que hubo en la constitución del cenobio, aunque lo más probable, como apuntan Colombás y Gost, es que hubo

63 AHN, Clero, Leg. 7734, s.f.

64 Esta "madona" Urraca podría ser, tal vez, Urraca Tenorio, hermana del arzobispo de Toledo Pedro Tenorio, que se acabó afincando definitivamente en Segovia; C. Olivera, Exiliados de Portugal en Segovia, pp. 186-194.

65 También el 21 de septiembre Juan I ordenaba a los alcaldes y merino de Valladolid cerrar la puerta que abrió Diego del Corral "el mozo" en las "casas de su morada fasta el río Esgueva". AHN, Clero, Leg. 7735, s.f.

${ }_{66}$ G.M. Colombás; M.M. Gost, Estudios, Apéndice II. 
problemas para encontrar un número suficiente de religiosos dispuestos a vivir en clausura completa ${ }^{67}$. De hecho no se llegó a cubrir la cifra inicialmente prevista de dieciocho monjes. No vamos a reiterar aspectos conocidos sobre la fundación, pero merece la pena insistir en que la fórmula empleada por Juan I era inusual, pues estaba fundando un monasterio de clausura junto a un espacio palatino usado por la corte en el que además ejercían su labor litúrgica los capellanes reales, con la peculiaridad de que éstos y los monjes compartían algunos lugares de uso litúrgico.

Llama la atención el hecho de que el rey no concediera al monasterio algún señorío, sino que se limitara a dotarlo con el edificio, la huerta y algunas rentas vallisoletanas. En este punto san Benito el Real vuelve a tener unos rasgos algo peculiares. La explicación más plausible es que el proyecto de Juan I consistía, como ya lo hemos apuntado, en fundar un monasterio palatino o, si se prefiere, un monasterio de clausura con un anexo de estancias reales, de tal modo que el sostenimiento de la pequeña comunidad de dieciocho monjes estaría asegurado por las rentas propias y quizás por las aportaciones derivadas de la presencia frecuente del monarca. Huelga decir que no estaba prevista a estas alturas la creación de una congregación de monasterios.

Juan I falleció inesperadamente en Alcalá de Henares el 9 de octubre de 1390 sin haber sellado el privilegio fundacional. Para los historiadores antiguos del monasterio este defecto formal fue un serio problema que estuvo a punto de arruinar el cenobio recién nacido. Según Mancio de Torres los monjes hicieron gestiones infructuosas ante los tutores de Enrique III y ante la hermana del difunto, Leonor de Navarra, para rellenar de algún modo el vacío legal. Probablemente fray Mancio pretendía poner de relieve la precariedad que padecieron los primeros monjes para así destacar su heroicidad y sacrificio. Es posible que el problema legal tuviese cierta relevancia, pero en realidad el argumento no es del todo convincente porque los documentos del propio archivo revelan una realidad algo diferente.

Tenemos noticia de las confirmaciones que la regencia de Enrique III hizo entre 1391 y 1393. Durante las Cortes de Madrid, entre marzo y abril de 1391, llegaron las primeras cartas reales que aseguraban la supervivencia de san Benito tanto en lo jurídico como en lo económico. La confirmación más importante se refiere a la donación del alcázar junto con las rentas asignadas para el sostenimiento material ${ }^{68}$. Incluso se confirmó la propiedad de los

67 Ibidem, pp. 26-27.

68 El 28 de marzo de 1391 Enrique III confirma a san Benito el privilegio de Juan I (1390, septiembre, 21, Turégano) por el que funda el monasterio en el alcázar de Valladolid, y además confirma las 600 fanegas de trigo y 1.200 cántaras de vino anuales en lo salvado de las tercias de Valladolid, junto con los 15.000 maravedíes en el servicio de los judíos de la aljama vallisoleta- 
antiguos baños que la reina Beatriz había concedido a García Fernández de Velliza $^{69}$ y que ya pertenecían a los benedictinos.

El propio Enrique III confirmó y amplió los privilegios nada más asumir la gobernación de sus reinos en agosto de 1393. Por ejemplo, el 19 de septiembre ordenó a las justicias de Valladolid que se cumpliese una carta de su padre que prohibía a Diego del Corral el mozo abrir una puerta en sus casas fasta el rrio Esgueva porque perjudicaba al monasterio; ahora exigía que ese mandato su cumpliese sin alongamiento de maliçia, si así es ${ }^{70}$. El tono personal de la orden denota un buen conocimiento de la situación que vivían los monjes. Algo parecido sucede con las confirmaciones relacionadas con el sostenimiento económico, donde se definen los bienes que ha de percibir la institución. Durante su estancia en la villa el monarca confirmó las tercias reales que Juan I había otorgado, precisando los detalles del cobro con el fin de evitar los inconvenientes que se venían produciendo ${ }^{71}$. Lo mismo sucedió con los quince mil maravedíes asentados en la aljama de los judíos de la villa ${ }^{72}$.

La protección del rey se extendió a otros asuntos económicos que no estaban ligados a la dotación fundacional, como los servicios que fueron cobrados al clero castellano, y que los monjes de san Benito el Real lograron evitar. En 1397 Enrique III aceptó una protesta presentada por el primer prior, fray Antonio de Ceinos (o Zelinos), contra las autoridades urbanas que pretendían imponer el repartimiento que afectaba al conjunto de los clérigos de la villa $^{73}$. Esta exención será confirmada en $1399^{74}$ y $1400^{75}$.

na. AHN, Clero, Carp. 3445, n 18; citado por F. de A. Veas, Itinerario, $n^{\circ} 31$. Otra confirmación similar fechada a 4 de abril de 1391; AHN, Clero, Leg. 7734, s.f.

${ }^{69}$ Fechado a 20 de abril de 1391; AHN, Clero, Carp. 3445, no 8.

70 Fechada en Lerma el 19 de septiembre de 1393; AHN, Clero, Leg. 7734, s.f.

${ }^{71}$ El 3 de diciembre de 1394, desde Valladolid, Enrique III ordena que se entregue a san Benito lo que le corresponde de las tercias de Valladolid sin el obispado de Simancas. Original con la firma autógrafa del rey; AHN, Clero, leg. 7734, s,f. Hay traslado fechado en Valladolid el 17 de abril de 1395; AHN, Clero, Leg. 7731, s.f.

72 El 16 de agosto de 1401, desde Segovia (traslado de 8 de noviembre de 1409), Enrique III ordena a la aljama de Valladolid que se paguen los 15.000 maravedíes conforme a la nueva equivalencia. AHN, Clero, Leg. 7735 , s.f.

73 El 12 de noviembre de 1397, desde el monasterio de santa María de Pelayos, Enrique III ordenaba a las autoridades urbanas de la villa que no impusiesen a los monjes de san Benito el repartimiento que se había de coger entre los clérigos, indicando que las propiedades y rentas del cenobio estaban exentas por orden de Juan I. AHN, Clero, Leg. 7734, s.f.

74 El 12 de mayo de 1399, desde Segovia, Enrique III ordena a los abades y cabildos de Palencia y Valladolid, así como a las justicias de sus reinos, que no impongan derramas sobre los clérigos de san Benito, pues va en contra de lo dispuesto por su padre. AHN, Clero, Leg. 7735 , s.f.

75 El 15 de junio de 1400, desde Salamanca, Enrique III ordena al abad de Valladolid que no imponga a los monjes de san Benito el servicio que se ha derramado entre los clérigos de sus reinos. AHN, Clero, Leg. 7734, s.f; hay copia moderna en Leg. 7735, s.f. 
Enrique III también dio facilidades al primer prior para proveer al crecimiento de la comunidad. Si en 1390 no se había cubierto el cupo inicialmente previsto de veintitrés monjes, sólo cuatro años más tarde el número de candidatos dispuestos a profesar la austera vida enclaustrada superaba con creces esa cifra. Fue entonces cuando el prior Ceinos consiguió del rey una autorización para llegar a cuarenta y tres ${ }^{76}$. El dato tiene su interés para entender la creciente fama de santidad del cenobio y para calibrar la progresiva pérdida del uso palaciego en beneficio del monástico. Probablemente por estas fechas se dotó la capellanía real perpetua para rezar por los reyes antepasados; aquello era un vestigio de la primitiva voluntad de Juan I al erigir san Benito ${ }^{77}$.

Fray Antonio de Ceinos abandonó en 1398 el cargo de prior para regresar a Sahagún como abad. La documentación que se ha conservado sobre la época final de su vida (hasta 1417) no guarda relación con su etapa vallisoletana ni parece que tratara de introducir la reforma en su abadía ${ }^{78}$. Aún seguía sin verse en el horizonte inmediato la futura expansión del régimen de vida observante mediante una congregación. Algo parecido sucederá con el nuevo prior, fray Juan de Madrigal ${ }^{79}$, cuyo mandato durará nada menos que hasta 1421. San Benito el Real crece bajo su mandato en prestigio y fama de santidad, cosa bien visible en el número de vocaciones, pero seguirá siendo al fin y al cabo un monasterio de clausura con importancia local. Algunos individuos y familias del ámbito cortesano fijarán sus ojos en la nueva fundación. El aumento progresivo de las donaciones particulares y el paralelo estancamiento de las mercedes reales induce a pensar que en los años de la regencia de Juan II se consolidó la vinculación del cenobio a la sociedad vallisoletana en detrimento de la estrecha relación que había mantenido con la corona bajo Juan I y Enrique III.

La nueva señora de la villa desde 1406, Catalina de Láncaster, debió preferir otras moradas a la de san Benito, como el convento dominico de san Pablo o sus propias casas vallisoletanas, que serán donadas más tarde al condestable Ruy López Dávalos, donde se fundará a comienzos del siglo XV el convento de san Agustín. Por lo demás, la reina regente adopta el modelo de convento-palacio en alguna de sus construcciones más célebres, como el que

76 Albalá de Enrique III (28 de febrero de 1394) al prior de san Benito autorizándole a admitir otros 20 monjes además de los 23 previstos inicialmente por Juan I (18 profesos y 5 legos), ya que muchos candidatos así se lo habían pedido. AHN, Clero, Leg. 7734, s.f.

77 Conocemos el dato a través de la capellanía que Juan II ordenó fundar en san Benito, mediante una cédula firmada en Segovia el 11 de diciembre de 1427, inserta en otra posterior del mismo rey firmada en Valladolid el 18 de noviembre de 1431; AHN, Clero, leg. 7715, s.f.

78 Hay noticias de su complicada gestión en Sahagún en V. A. Álvarez Palenzuela, Colección diplomática, pp. 144-175.

79 Otros detalles de su vida en E. Zaragoza, Abadologio, p. 208. 
manda levantar en las proximidades de la aldea de Nieva. En efecto, el convento dominico de santa María la Real de Nieva tendrá unas estancias reales adosadas al convento para alojar a la reina y su séquito durante las estancias cortesanas en la villa ${ }^{80}$. Este convento será visitado con relativa frecuencia por la corte en tiempos de Juan II y Enrique IV.

\section{Exiliados DE Portugal EN EL ENTORNO DEL MONASTERIO}

Nos queda, por último, la cuestión de la presencia de exiliados de Portugal en el entorno del monasterio. El segundo prior, Juan de Madrigal, no sólo gobernó los asuntos de su comunidad sino que mantuvo un contacto cercano con algunas familias que vivían en las inmediaciones del san Benito. Conocemos esta vertiente de su mandato gracias a los documentos del archivo que aluden a las propiedades que fue reuniendo durante aquellos años con el fin de completar el patrimonio monástico en el barrio de Rehoyo. Los textos demuestran que el prior se interesó por cuestiones que iban más allá de las compras, permutas o donaciones testamentarias: fue capaz de actuar incluso como consejero familiar. Es significativo que los antiguos servidores de la reina Beatriz aparezcan con frecuencia en los papeles que pasaron por sus manos. Aunque la mayor parte de esos servidores no gozaba de una posición social sobresaliente, hay excepciones singulares.

El caso más llamativo es el de Inés Alfonso de Bendaña, una de las grandes damas portuguesas exiliadas. Su nombre figura en el Libro de los bienhechores con el nombre de Inés Alfonso de Abrio (sic, tal vez por Abreu $)^{81}$. Fue una de las primeras benefactoras de san Benito y de las más generosas. Su marido, Gonzalo Vázquez de Acevedo, primer mariscal de Portugal, había sido uno de los caídos portugueses más ilustres en la batalla de Aljubarrota y un hijo de ambos, Alvar González de Acevedo, también había perdido la vida en la misma jornada. El precio de sangre pagado por doña Inés había sido de los más altos entre los que se habían refugiado en Castilla; como otros muchos sufrió la consabida confiscación de todos sus bienes en su país de origen. Por este motivo Juan I le recompensó con un juro anual de 15.000 maravedíes en la cabeza de pecho de los judíos de Sevilla ${ }^{82}$. Era una suma muy digna, al menos si se compara con el nivel de rentas que tenían las prin-

80 M. González Herrero, Tensiones históricas, pp. 211-224.

81 G.M. Colombás, El Libro de los bienhechores, p. 349.

82 Le fue concedido el juro en las Cortes de Briviesca, el 4 de diciembre de 1487; AHN, Clero, Leg. 7704, s.f. 
cipales familias de la alta nobleza sevillana de la época ${ }^{83}$, pero la destrucción de la judería hispalense en 1391 le dejó sin posibilidad alguna de cobrar lo que le correspondía. Enrique III accedió en 1398 a traspasar el juro a la carne cristianega de Valladolid y a la carne y vino judiegos de la misma villa ${ }^{84}$. Pero los problemas con el cobro se repitieron por cuestiones burocráticas hasta que la reina Beatriz intercedió personalmente en 1401 para que se situara esa suma en lo salvado de la misma renta, cosa que finalmente se cumplió ${ }^{85}$. Como puede verse, la reina portuguesa se interesaba por la situación de sus cortesanos y es sintomático que Inés Alfonso optara por instalarse finalmente en la villa del Esgueva al amparo de su señora. La vinculación con san Benito formaba parte de aquella relación.

En efecto, Inés Alfonso acabó teniendo una relación muy estrecha con el monasterio. Uno de sus nietos, Juan de Acevedo, profesó como monje benedictino en 1411 bajo el prior Juan de Madrigal; con el tiempo acabará siendo el prior que inicie la expansión de la congregación en 1431. No estamos ante un monje anónimo entre otros de origen portugués, sino ante uno de los más decisivos en la historia de san Benito el Real. En el momento de entrar en religión fray Juan cedió a su abuela paterna -la citada Inés Alfonso- todos los derechos que le correspondían en Portugal y Galicia ${ }^{86}$ por sus abuelos maternos -el conde de Ourem, Juan Fernández de Andeiro ${ }^{87}$ y su mujer- como muestra de desprendimiento y pobreza. El primer testigo que figura al pie del documento de renuncia es fray Juan de Madrigal.

Inés Alfonso decidió en 1414 donar al monasterio la parte de esos bienes y derechos que correspondían a Galicia -no incluía los de Portugalen concepto de limosna para que los monjes rezasen por los antepasados de su nieto ${ }^{88}$. Fue un gesto más testimonial que efectivo porque los benedictinos jamás percibieron rentas o propiedades gallegas, ya que la donación no de-

83 El padrón sevillano de 1384 indica que los patrimonios de la alta nobleza sevillana oscilaban entre los 50.000 y los 10.000 maravedíes anuales; R. Sánchez Saus, Las élites políticas bajo los Trastámara, pp. 33-48.

${ }_{84}$ El rey le traspasó los 15.000 maravedíes al obispado de Ávila el 29 de marzo de 1398 (AHN, Clero, Leg. 7704, s.f.) pero el 29 de junio las asentó en las citadas rentas vallisoletanas (AHN, Clero, Leg. 7704, s.f.).

85 Enrique III ordenó a sus contadores el 15 de enero de 1401 que se cumpliese el ruego de la reina Beatriz en favor de Inés Alfonso; AHN, Clero, Leg. 7704, s.f.

86 Se trata de una renuncia genérica de los bienes que le pudiesen corresponder en Galicia; no se especifican los derechos o propiedades ni tampoco los lugares; AHN, Clero, Leg. 7706, s.f.

87 Una hija del conde de Ourem, Sancha de Andeiro, se había casado con Álvar González de Acevedo, el hijo de Inés Alfonso que había muerto en Aljubarrota; M.J. da Costa Felgueiras Gayo, Nobiliário, p. 549.

${ }_{88}$ La donación de Inés Alfonso a san Benito está fechada en Valladolid el 25 de agosto de 1414. AHN, Clero, Carp. 3449, nº 13. Hay una ratificación de esta donación con la misma fecha 
finía con claridad su contenido exacto; era más bien una muestra de agradecimiento de la viuda hacia la comunidad. La relación entre la ilustre viuda y los monjes no termina aquí. Cuando Inés Alfonso ordenó su testamento en 1419 pidió que su cuerpo fuera enterrado en san Benito y que su nieto Juan de Acevedo heredara 3.500 maravedíes de los 15.000 que ella tenía del juro vallisoletano ya citado, ordenando que el monasterio lo heredara después de la muerte de su nieto ${ }^{89}$. En este caso el deseo de la donante fue cumplido a la perfección y en los años posteriores el juro fue cobrado sin mayores complicaciones gracias a las sucesivas confirmaciones que llegan hasta el reinado de Enrique IV.

La documentación del monasterio también conserva una apreciable cifra de referencias a servidores de la reina Beatriz -algunos de ellos portugueses- que vivieron de forma estable en Valladolid, sobre todo en el barrio de Rehoyo. El arco cronológico de estas noticias abarca el primer tercio del siglo XV, especialmente su segunda década, es decir, la época en la que sobrevivió toda aquella generación de expatriados antes de esfumarse definitivamente de la escena con el transcurso del tiempo. El barrio mismo acabará siendo absorbido a fines del siglo XV debido a las ampliaciones sucesivas de la cerca del propio monasterio. Los benedictinos conservaron los papeles que demostraban la propiedad sobre las casas y huertas que fueron comprando o recibiendo por donación, y entre esos papeles aparecen los servidores de la reina. Estas referencias confirman la faceta palaciega que tuvo en sus primeros tiempos el viejo alcázar vallisoletano antes de desaparecer por completo ante el crecimiento del monasterio.

La impresión general que deja la lectura de estas fuentes es que el barrio de Rehoyo era un espacio de reducidas dimensiones poblado por familias de medianos o escasos recursos pero con una estrecha relación con el alcázar-monasterio. Por lo que respecta a los servidores de la reina Beatriz, parece que se establecieron allí precisamente porque estaban al servicio de su señora, aunque no hay alusiones directas a la presencia de la reina en el interior de los palacios reales de san Benito. En este sentido cabe la posibilidad de que doña Beatriz utilizara las cercanas casas de la reina que más adelante donará Catalina de Láncaster a Ruy López Dávalos ${ }^{90}$ para fundar el convento de san Agustín o, tal vez, otras moradas diseminadas por la

en AHN, Clero, Leg. 7729, s.f. Así mismo hay una reseña de esta donación en AHN, Clero, Libro 16771 , f. $57 \mathrm{v}$.

${ }^{89}$ El testamento está fechado el sábado 17 de junio de 1419. AHN, Clero, Leg.7704, s.f. Hay copia del año 1451 en AGS, EMR, Mercedes y Privilegios, Leg. 10, f. 72.

${ }_{90}$ Las antiguas casas de la reina acabaron siendo el monasterio de san Agustín, muy cercano al de san Benito; AHN, Clero, carp. 3443, nº 3 y 15. Véase A. Rucquoi, Valladolid en la Edad Media, II, p. 57. 
villa, como el convento de La Merced ${ }^{91}$ o bien las casas que pertenecieron al adelantado de Cazorla, Alfonso Tenorio ${ }^{92}$, sin descartar otras posibilidades. En el momento de redactar sus testamentos algunos de estos servidores agradecían -o devolvían en ocasiones- la ayuda recibida en el pasado. Tanto la reina como el cenobio se ocuparon de su suerte en los años difíciles del destierro.

Uno de los ejemplos más ilustrativos es el de los hermanos Vasco y Alfonso Yáñez, escuderos de la reina Beatriz, probablemente portugueses, que aparecen citados entre 1404 y 1418 en diversos actos jurídicos. Vasco Yáñez -que también se autodefine como criado de la reina- actuó como testigo en varios testamentos de los vecinos de Rehoyo en $1404^{93}, 1408^{94}$ y $1418^{95}$. Conocemos su patrimonio gracias a un documento de 1414 donde se compromete a cumplir toda una serie de obligaciones que había estipulado su mujer, Leonor González, que había designado a san Benito el Real como heredero universal de sus bienes. Leonor reservó el usufructo de la mitad a su marido aunque con la obligación de dejarlo todo a los benedictinos en el momento de morir ${ }^{96}$. Se advierte que el patrimonio acumulado por este matrimonio -del que no hubo descendencia- pertenecía íntegramente a la esposa, ya que fue ella la que dispuso el destino final de todos los bienes. Podemos suponer que el viudo perdió sus propiedades portuguesas al igual que la mayoría de los exiliados de su generación, pero no lo sabemos. Al menos mantuvo una cierta posición durante sus últimos años de vida, la suficiente como para nombrar un administrador -Nicolás Alfonso, hijo del contador Pedro Alfonso- que se

91 Fundado en las casas de la reina Leonor Téllez, madre de Beatriz de Portugal; C. Olivera, Beatriz de Portugal, p. 253.

92 Los regidores de Valladolid donaron en enero de 1410 las torres y parte de la cerca que estaban enfrente de las casas del adelantado de Cazorla, Alfonso Tenorio, y de su mujer; AHN, Clero, Carp. 3448, $\mathrm{n}^{\circ}$ 14. La reina Beatriz solía hospedarse en las casas segovianas del adelantado cuando la corte recalaba en la ciudad del Eresma; C. Olivera, Exiliados de Portugal en Segovia, p. 177-198.

93 Toma de posesión de las casas que fueron de Urraca Gutiérrez, difunta, en el barrio de Rehoyo, según se manda en su testamento fechado en Valladolid el 31 de octubre de 1404. Entre los testigos presentes están Vasco y Alfonso Yánez, "escuderos de la reina doña Beatris vesinos aquí en Valladolid". AHN, Clero, Carp. 3447, no 14.

94 Carta de venta de la casa y corral en Rehoyo que otorgó Alfonso Fernández el 6 de mayo de 1408 a favor del monasterio, junto a la huerta de san Benito, a la ronda. Entre los testigos aparece Vasco Yáñez, criado de la reina Beatriz. La toma de posesión de realiza el mismo día estando presentes los mismos testigos. AHN, Clero, Carp. 3448, $\mathrm{n}^{\circ} 12$.

95 Testamento de María Fernández, moradora en la collación de san Julián, viuda de Juan Fernández de Bolaños. Entre los testigos figura Vasco Yáñez, criado de la reina Beatriz. Está fechado en Valladolid el 21 de agosto de 1418. AHN, Clero, Carp. 3450, nº 2 y 3.

96 Obligaciones de Vasco Yáñez, "criado de nuestra señora la rreyna doña Beatris", vecino de Valladolid, en relación con los bienes que le dejó en testamento su mujer Leonor González, ya difunta. Fechado en Valladolid el 20 de enero de 1414; AHN, Clero, Leg. 7716, s.f. 
encargó de la gestión y explotación de las propiedades que le había dejado su mujer $^{97}$.

Otro matrimonio relativamente bien documentado es el de Alfonso Martínez de Lisboa (Lixbona), criado de la reina, y de Sancha Lorenzo, probablemente portuguesa. Sabemos que este servidor de la reina ya vivía en 1412 en unas casas de su propiedad en el barrio de Rehoyo ${ }^{98}$ y que en 1429 vendió la mitad al escribano Alonso González de Valladolid ${ }^{99}$. Al año siguiente ya había fallecido y sus propiedades pasaron a los benedictinos por la correspondiente transmisión testamentaria ${ }^{100}$.

No es posible determinar con seguridad si algunos de los personajes que se autodefinen como criados de la reina son portugueses o castellanos, como Alfonso Fernández, que figura en 1412 como testigo en una compraventa de unas casas en Rehoyo ${ }^{101}$. Lo mismo sucede con Diego Núñez, criado de la reina, que en 1424 aparece como testigo en una donación ${ }^{102}$. Hay otros vecinos del barrio que no aluden a la reina pero parecen proceder de Portugal, como Martín González de Almeida, casado con Marina Rodríguez, que compran unas casas en 1412; entre los testigos de esta operación figura un tal Pedro Fernández de Guzmán que se identifica como ome de la rreyna doña Beatris ${ }^{103}$. También en-

97 Además de las casas principales de Valladolid donde moraba Vasco Yáñez, el matrimonio tenía otras "ocho casas pequenas todas de una puerta, dentro del corral", en Rehoyo; una viña en término de Bambilla de unas cinco aranzadas "en la cuesta que dizen de Oterdeaguila"; una viña de tres aranzadas y media en término de Pedrosilla; en Fuentes de Duero tenían otras casas con parte de sus corrales, así como 17 aranzadas y una quinta de viñas, en diez pedazos; en Tudela de Duero tenían una viña de aranzada y media en el pago llamado fray Gonzalo; finalmente poseían en Valladolid una tierra de pan llevar, en Berrocal; ibidem.

98 Venta de una casa en Rehoyo propiedad del moro Mahomad, hijo del maestro Haça altamiero, al monasterio de san Benito. La casa está en la calle que va del postigo al río y a los molinos de la Canaleja. Linda con las casas de su hermana Mariame (Miriam) que son ahora de Juan Hervás, escudero del infante don Fernando, las casas de Alfonso Martínez de "Lisbona", criado de la reina Beatriz, las casas del escribano Toribio Sánchez, la huerta del monasterio de san Agustín y la puerta de entrada de la calle pública. Fechada en Valladolid el 28 de enero de 1412; AHN, Clero, Carp. 3449, n $^{\circ} 2$.

99 La compra está fechada el 17 de octubre de 1429. Las casas en cuestión lindaban con el monasterio de san Benito. AHN, Clero, Leg. 7729, s.f. Hay copia en AHN, Clero, Libro 16771, f. 62 .

100 Venta efectuada el 2 de agosto de 1430 por la que el escribano Alonso González y su mujer Marina González venden a san Benito las casas de Alonso Martínez de Lisboa y su mujer Sancha Lorenzo, "que Dios perdone", por 900 maravedíes; AHN, Clero, Carp. 3454, n 3.

101 La venta al monasterio de san Benito está otorgada por Catalina González, mujer de Ferrand González, y Toribio Sánchez, escribano, hijo de la citada Catalina. Está fechada el 3 de febrero de 1412; AHN, Clero, Carp. 3449, nº 3.

102 Los donantes son Andrés Gutiérrez de Cuvillana y su mujer Mencía Rodríguez; conceden al monasterio de san Benito unas viñas. Está fechada en Valladolid el 23 de septiembre de 1424. AHN, Clero, Carp. 3452, nº 12.

103 AHN, Clero, Carp. 3449, n 5. Estas casas serán vendidas al monasterio en 1421; AHN, Clero, Carp. $3451, n^{\circ} 1$. 
contramos portugueses que no están al servicio de la reina aunque sí lo están al de ciertas personas muy ligadas a ella, como Gonzalo Vázquez, que firma como testigo ${ }^{104}$ indicando que es portugués, criado de doña Teresa de Meira, aya de doña Beatriz ${ }^{105}$. Todos estos ejemplos confirman la faceta cortesana o palaciega del monasterio en sus primeros tiempos.

\section{CONCLUSIÓN}

En 1431 la corte castellana pasó definitivamente página en todo lo relacionado con la reivindicación de la corona portuguesa desde el instante en que Juan II firmó el tratado de Medina del Campo/Almeirim con João I de Avís, el viejo rival de Juan $\mathrm{I}^{106}$. No fue fácil tomar una decisión de este calibre. En el Consejo Real hubo airadas protestas de los descendientes de aquellos caballeros que habían perdido la vida en Aljubarrota. Pero a pesar del descontento los Trastámara renunciaron a cualquier derecho dinástico que les pudiera venir a través de la reina Beatriz, de modo que ya no era necesario seguir rezando por la recuperación del reino de Portugal. El resto de las intenciones fundacionales de Juan I seguían en pie, pero esta última había perdido su razón de ser. En ese momento el monasterio había cumplido cuarenta años de vida y sus destinos estaban regidos - paradojas de la historia- por el prior Juan de Acevedo, nieto de uno de los caballeros portugueses caídos precisamente en la batalla de Aljubarrota.

Tal vez sea una casualidad, pero en esas mismas fechas se inició el germen de la congregación vallisoletana con la fundación del monasterio de Calabazanos ${ }^{107}$. Aunque fue una experiencia corta en el tiempo, la nueva fundación abría la senda hacia la creación de nuevos centros benedictinos o a la integración de otros que deseaban adoptar el estilo austero y observante de la comunidad vallisoletana. El prior Juan de Acevedo aún tendría tiempo bajo su mandato de extender la observancia al de san Juan de Burgos. Aunque a estas alturas era un poco pronto para vislumbrar la formidable expansión que ven-

104 Aparece en las obligaciones ya citadas de Vasco Yáñez, "criado de nuestra señora la rreyna doña Beatriz"; AHN, Clero, Leg. 7716, s.f.

105 Estuvo casada con el portugués Fernán González de Sousa; según el cronista Fernão Lopes este matrimonio fue organizado por la reina Leonor Téllez, mujer de Fernando I; cf. C. Olivera, Beatriz de Portugal, p. 263.

106 El texto firmado por los portugueses está publicado en Monumenta Henricina, IV, pp. 18-53. En las pp. 24-26 se incluye la solemne declaración de Juan II renunciando a los derechos dinásticos que le correspondían sobre la corona de Portugal.

107 Sobre las vicisitudes de la fundación bajo el prior Juan de Acevedo véase E. Zaragoza, Los generales, I, pp. 75-100; idem, Abadologio, p. 209. La toma de posesión está fechada el 15 de febrero de 1431; AHN, Clero, Leg. 7729, s.f. 
dría durante la segunda mitad del siglo XV, las bases del crecimiento estaban sólidamente establecidas gracias al prestigio del cenobio y a la labor rectora de su prior. En este contexto la faceta palaciega que había coexistido desde los primeros tiempos de la fundación tendía a remitir progresivamente. En el mismo año de la fundación de Calabazanos se estableció un acuerdo entre el prior Acevedo y el capellán real Juan Martínez de Valdecañas por el que éste se comprometía a ceder a los monjes la renta anual de 3.000 maravedíes que Juan II había dotado para el sostenimiento de la capellanía real que oficiaba en la capilla real del alcázar. Era una solución que permitía a los benedictinos nombrar a uno de los suyos como capellán real y evitar así la incómoda presencia de un clérigo ajeno a la vida conventual ${ }^{108}$. De algún modo los monjes estaban limitando por esta vía la interferencia de la realeza en su régimen de vida claustral.

Poco tiempo después, en mayo de 1432, Juan II otorgaba la ordenanza que ya hemos citado regulando la entrada del rey y sus cortesanos en el interior de la clausura, consolidando el estilo de vida claustral que tanta fama había cosechado hasta ese momento y que seguiría creciendo en lo sucesivo. El cabildo vallisoletano y el común de los fieles tendrían que conformarse con participar en las celebraciones litúrgicas que se oficiaban en la iglesia detrás de la reja de separación y recibir en ese espacio el sacramento de la confesión o los consejos ascéticos que proporcionaban los monjes. De este modo quedaba asegurada la clausura y el aislamiento de la comunidad. También se observa en este punto tan vital una victoria de los benedictinos frente a las entradas de la corte en un espacio acotado para el rezo y la vida conventual.

Sin embargo quedó en pie una faceta relativamente "mundana" en sus relaciones con el exterior: la utilización del monasterio como depósito de documentos y caudales pertenecientes a la corona y a las familias de los bienhechores. La seguridad que inspiraban los muros del viejo alcázar y la vida aislada de los monjes convertía a san Benito el Real en un lugar idóneo para conservar objetos de valor. La custodia de estos depósitos acabaría deparando algunos sobresaltos y amarguras, como la célebre incautación decretada por Juan II contra el contador mayor Fernán Alfonso de Robles en 1428, que tanto revuelo provocó en la villa y en el monasterio ${ }^{109}$.

En suma, la desaparición de la reivindicación castellana de la corona portuguesa, la progresiva extinción de las facetas palaciegas del monasterio

108 Juan Martínez de Valdecañas era bachiller en decretos y arcediano de Búbal en la iglesia de Orense. Los acuerdos están fechados el 16 y 18 de noviembre de 1431; AHN, Clero, leg. 7715 y 7731 , s.f.

109 Se ha ocupado de esta cuestión M. Diago, El contador Fernán Alonso de Robles, pp. 117-134.

ANUARIO de Estudios Medievales, 43/2, julio-diciembre 2013, pp. 799-832

ISSN 0066-5061, doi:10.3989/aem.2013.43.2.11 
(incluyendo la actividad de la capilla real y la actuación del capellán real), la definición más clara de la clausura y la progresiva incorporación del pequeño barrio de Rehoyo dentro de la cerca del monasterio, hicieron posible la superación de unos rasgos primigenios que habían dominado el estilo de vida de los años fundacionales. A partir del nacimiento de la congregación en 1431 la personalidad monástica de san Benito saldría reforzada y lista para influir decisivamente en la vida de otros centros benedictinos de la corona de Castilla. Los aspectos más vinculados a los anhelos políticos de Juan I habían pasado a la historia.

\section{BIBLIOGRAFÍA CITADA}

Álvarez Palenzuela, Vicente Ángel (ed), Colección diplomática del monasterio de Sahagún, vol. VII: (1300-1500), León, Centro de Estudios e Investigación san Isidoro, 1997.

Bustamante García, Agustín, San Benito el Real de Valladolid, de fortaleza a convento, en Rivera, J. (coord.), Monasterio de san Benito el Real. VI Centenario (1390-1990), Valladolid, Ayuntamiento de Valladolid, 1990, pp. 133-148.

Cantera Montenegro, Santiago, Los cartujos en la religiosidad y la sociedad españolas: 1390-1563, 2 vol, Salzburgo, Institut für Anglistik und Amerikanistik - Universidad de Salzburgo, 2000.

Cantera Montenegro, Santiago, Las relaciones de las cartujas de la provincia de Castilla con la monarquía: 1390-1598, en Mairabò Gralla, Concepció Bauçà de (ed), Prínceps i reis: promotors de l'orde cartoixà, Palma de Mallorca. Universitat de les Illes Balears, 2003, pp. 277-292.

Cañas Gálvez, Francisco de Paula, Colección diplomática de Santo Domingo el Real de Toledo. Documentos reales I: 1249-1473, Madrid, Sílex, 2010.

Castro Toledo, Jonás, Colección diplomática de Tordesillas, Valladolid, Diputación, 1981.

Cerro Herranz, María F., Documentación del monasterio de Guadalupe. Siglo XIV, Badajoz, Diputación, 1987.

Chueca Goitia, Fernando, Casas reales en monasterios y conventos españoles, Madrid, Xarait, 1983.

Colombás García, María; Gost, Mateo M., Estudios sobre el primer siglo de San Benito de Valladolid, Montserrat, Abadía de Montserrat, 1954.

Colombás García, María, El Libro de los bienhechores de san Benito de Valladolid, "Studia Monástica" 5 (1963), pp. 305-402. 
Cortes de los antiguos reinos de León y Castilla, II, Madrid, Real Academia de Historia, 1863.

Diago Hernando, Máximo, El contador Fernán Alonso de Robles: nuevos datos para su biografía, "Cuadernos de Historia de España" 75 (1998-1999), pp. 117-134.

Diago Hernando, Máximo, La tutela nobiliaria sobre los monasterios benedictinos castellanos en la baja Edad Media: relaciones entre los Velasco y el monasterio de san Salvador de Oña, "Hispania Sacra" 56 (2004), pp. 69-102.

Garcez Ventura, Margarida, O Messias de Lisboa. Um estudo de mitologia política (1383-1415), Lisboa, Edições Cosmos, 1992.

García Fernández, Ernesto (coord.), La Tierra de Ayala: Actas de las Jornadas de Estudios Históricos en conmemoración del 600 aniversario de la construcción de la torre de Quejana, Vitoria, Diputación Foral de Álava, 2001.

García Flores, Antonio; Ruiz Souza, Juan Carlos, El palacio de María de Molina y el monasterio de Las Huelgas de Valladolid: un conjunto inédito de yeserías decorativas hispanomusulmanas, en "Reales Sitios: revista del Patrimonio Nacional", 160 (2004), pp. 2-13.

García Oro, José, Cisneros y la reforma del clero español en tiempo de los Reyes Católicos, Madrid, CSIC - Instituto Jerónimo Zurita, 1971.

Felgueiras Gayo, Manuel José da Costa, Nobiliário de Famílias de Portugal, I, Braga, Carvalhos de Basto, 1992.

Gómez, Ildefonso M., El Paular y san Benito de Valladolid. Notas en torno a su motivación fundacional, "Yermo. Cuadernos de historia y espiritualidad monástica" 17/1-2 (1979), pp. 5-44.

González Herrero, Manuel, Tensiones históricas en torno a la fundación de santa María la Real de Nieva, "Estudios Segovianos" 91 (1994), pp. 211-224.

Ladero Quesada, Miguel Ángel, Mecenazgo real y nobiliario en monasterios españoles: los jerónimos (siglos XV y XVI), en Homenaje a José María Lacarra, "Príncipe de Viana", anejo 3 (1986), pp. 409-439.

López de Ayala, Pedro, Crónica de Juan I de Castilla, en Crónicas de los Reyes de Castilla, (ed. de Cayetano Rosell), Madrid, Biblioteca de Autores Españoles, t. LXVIII, vol. II, 1953.

López Fernández, Atanasio, Fray Fernando de Illescas, confesor de los reyes Juan I y Enrique III, "Archivo Ibero-Americano" 30 (1928), pp. 241-252.

Madrid, Ignacio de, Los monasterios de la orden de san Jerónimo en España, "Yermo. Cuadernos de historia y espiritualidad monástica" 5 (1967), pp. 114-116. 
Martín Montes, Miguel Ángel, El Alcázar real de Valladolid, Valladolid, Fundación Municipal de Cultura, 1995.

Martín Montes, Miguel Ángel; Moreda Blanco, Javier, Los 'Palacios' de san Benito el Real (Valladolid) y su ornamentación mudéjar, en V Congreso de Arqueología Medieval Española. Actas., vol. 2, Valladolid, Junta de Castilla y León-Consejería de Educación y Cultura, 2001, pp. 931-938.

Moreda Blanco, Javier, El Monasterio de San Benito el Real y Valladolid: arqueología e historia (catálogo de la exposición celebrada en junioagosto de 1996), Valladolid, Ayuntamiento de Valladolid, 1998.

Nieto Soria, José Manuel, Franciscanos y franciscanismo en la política y en la corte de la Castilla Trastámara (1369-1475), "Anuario de Estudios Medievales" 20 (1990), pp. 109-132.

Monumenta Henricina, IV, Coimbra, Comissão Executiva das Comemorações do Quinto Centenário da Morte do Infante Dom Henrique, 1962.

Nogales Rincón, David, La representación religiosa de la Monarquía castellano-leonesa: la Capilla Real (1252-1504), Madrid, Universidad Complutense, 2009, vol. I, p. 347. Tesis doctoral inédita. Disponible en: http://eprints.ucm.es/9819/1/T31467.pdf [consulta: 15/06/2011].

Olivera Serrano, César, Beatriz de Portugal. La pugna dinástica Avís-Trastámara, Santiago de Compostela, Instituto de Estudios Gallegos Padre Sarmiento - Xunta de Galicia, 2005.

Olivera Serrano, César, Exiliados de Portugal en Segovia a fines del siglo XIV, "Estudios Segovianos" 106 (2007), pp. 186-194.

Olivera Serrano, César, La memoria de Aljubarrota en Castilla, en Actas das VI Jornadas Luso-Espanholas de Historia Medieval, vol. II, Universidade de Coimbra, 2009, pp. 277-294.

Pérez de Guzmán y Gallo, Juan, Memoria sobre la Orden de la Banda de la Caballería de Castilla, "Boletín de la Real Academia de la Historia" 72 (abril 1918), pp. 436-465.

Revuelta Somalo, José María, Renovación de la vida espiritual, en Historia General de España y America, V: Los Trastámara y la unidad española, Madrid, Rialp, 1981, pp. 189-224.

Rivera, Javier (ed), VI Centenario: Monasterio de san Benito el Real, 13901990, Valladolid, Ayuntamiento de Valladolid - Instituto Nacional de Empleo - Escuela Taller Monasterio de San Benito, 1990.

Rodríguez Martínez, Luis, Historia del monasterio de san Benito el Real de Valladolid, Valladolid, Caja de Ahorros Popular - Ateneo, 1981.

Rodríguez Velasco, Jesús D., El debate sobre la caballería en el siglo XV: la tratadística caballeresca castellana en su marco europeo, Valladolid, Junta de Castilla y León-Consejería de Educación y Cultura, 1986. 
Rucquoi, Adeline, Valladolid en la Edad Media, II, El mundo abreviado, Valladolid, Junta de Castilla y León-Consejería de Educación y Cultura, 1988.

Ruiz Souza, Juan Carlos, Santa Clara de Tordesillas: nuevos datos para su cronología y estudio: relación entre Pedro I y Muhammad V, "Reales Sitios. Revista del Patrimonio Nacional" 130 (1996), pp. 32-40.

Ruiz Souza, Juan Carlos, Santa Clara de Tordesillas, en González Alarcón, M.T.; Valdeón Baruque, J. (eds.), Los Reales Sitios, vol. 6, Real Monasterio de santa Clara de Tordesillas, Madrid, Patrimonio Nacional, 2005, pp. 19-27.

Sánchez Herrero, José, Fundación y desarrollo de la Orden de los Jerónimos, 1360-1561, "Codex Aquilarensis. Cuadernos de investigación del monasterio de Santa María la Real" 10 (1994), pp. 63-95.

Sánchez Saus, Rafael, Las élites políticas bajo los Trastámara. Poder y sociedad en la Sevilla del siglo XIV, Sevilla, Universidad de Sevilla, 2009.

Sánchez Sesa, Rafael, Don Pedro Tenorio y la reforma de las ordenes monásticas en el último tercio del siglo XIV, "En la España Medieval" 18 (1995), pp. 289-302.

Santos Díez, José Luis, La encomienda de monasterios de la Corona de Castilla. Siglos X-XV, Madrid - Roma, CSIC, 1961.

Suárez Fernández, Luis, Reflexiones en torno a la fundación de san Benito de Valladolid, en Homenaje a fray Justo Pérez de Urbel, I, Silos, Abadía, 1976, pp. 433-443. (Studia Silensia; 3).

Suárez Fernández, Luis, Historia del reinado de Juan I de Castilla, I (Estudio), Madrid, Universidad Autónoma de Madrid, 1977.

Veas Arteseros, Francisco de Asís, Itinerario de Enrique III, Murcia, Universidad de Murcia, 2003.

Zaragoza Pascual, Ernesto, Los generales de la congregación de San Benito de Valladolid, 6 vols., Zamora, Abadía de Silos, 1975-1976.

Zaragoza Pascual, Ernesto, La práctica de la contemplación entre los monjes benedictinos reformados españoles durante los siglos XIV y XV, "Nova et Vetera" 2 (1976), pp. 183-199.

Zaragoza Pascual, Ernesto, Libros que alimentaban la vida espiritual de los benedictinos vallisoletanos del siglo XV, "Nova et Vetera" 3 (1977), pp. 267-279.

Zaragoza Pascual, Ernesto, La práctica de la oración metódica entre los benedictinos españoles del siglo XVI, "Nova et Vetera" 3 (1977), pp. 107-121.

Zaragoza Pascual, Ernesto, Reglas y avisos para los que no están ejercitados en la oración, "Nova et Vetera" 9 (1980), pp. 37-49. 
Zaragoza Pascual, Ernesto, Cronistas generales de la congregación de san Benito de Valladolid, "Boletín de la Real Academia de la Historia" 189/1 (1992), pp. 89-126.

Zaragoza Pascual, Ernesto, Abadologio del monasterio de san Benito el Real de Valladolid, "Investigaciones Históricas: época Moderna y Contemporánea" 23 (2003), 203-260.

Zunzunegui Aramburu, José, La legación en España del cardenal Pedro de Luna, 1379-1390, "Miscellanea Historiae Pontificiae" 11 (1943), pp. 83-137.

Fecha de recepción del artículo: enero 2012

Fecha de aceptación y versión final: junio 2012 